\title{
The Scope and Challenges of Rural Surgical Practice in Nigeria
}

Abstract

\section{JI Umunna}

Jasman Hospital

Udo-Ezinihitte

Mbaise, Imo State, Nigeria

Affiliation:

Department of Anatomy

College of Medicine and

Health Sciences

Evan Enwerem

University,(IMSU) Owerri

All Correspondence:

Dr JI Umunna

Jasman Hospital Ltd, Udo

E-mail:

Jasumunna@gmail.com
Background: Rural surgical practice is the practice of Surgery under conditions of limited resources which brings surgical services to the doorsteps of the rural Populace, majority of whom are poor.

\begin{abstract}
Aims: The aim of this paper is to highlight rural surgical practice in Nigeria.
Materials and Methods: A review of personal experiences in rural surgery and interaction with other practitioners in the field as well information gathered at Rural Surgery conferences in Nigeria and abroad.

Results: Scope of surgery performed is commonly usually limited by infrastructure, manpower and funding. Procedures include fields as Obstetrics and Gynaecology, Urology, Orthopaedics, Ear Nose and throat, Anaesthesia as well as General Surgery. A high proportion is contributed by emergencies especially Caesarian Sections, removal of foreign bodies from the ear, nose and throat, initial management of simple fractures, Hip-pinning, appendectomies, relief of intestinal obstruction, suprapubiccystostomies, catheterization and management of ruptured ectopic tubal pregnancies. The procedures are carried out by General Duty doctors with only a few surgeons in established self-owned practices. Challenges include poor living conditions, poor accessibility, lack of infrastructure and equipment, lack of suitably trained assistants, inadequate schools for their children, lack of suitable jobs for spouses. In spite of difficulties Rural Surgery in Nigeria has come to stay and is growing especially with formation of Rural Surgical Practitioners in Nigeria.
\end{abstract}

Conclusion: Rural surgical practice is feasible in Nigeria and should be encouraged by the Government as it forms an important arm of Healthcare delivery in Nigeria.

Key Words: Rural, Surgery, Scope, Challenges, Limited resources, Poverty

\section{Introduction}

$\mathrm{S}$ imply defined, Rural Surgical practice means surgical practice carried out in the rural area. Udwadia T.E. has defined it as "need-based multidisciplinary surgery under resource constraint to make surgical care accessible to the rural community." Malpane A. says it is not an easy game nor is it the final resort of the unsuccessful ${ }^{2}$. Rural Surgery brings surgical services to the door steps of rural residents and obviates the problems involved in their travelling long distances to the city, several kilometers away, for surgical attention, even of the simplest types.

Hospital establishments in rural Nigeria may be owned by government or non-governmental agencies, but most rural hospitals are self- and soleowned by private medical practitioners. These private hospitals fall into what are termed "small hospitals" staffed by a sole practitioner but may be larger with more than one general surgeon and even super specialists on visitation ${ }^{3}$.

\section{Definition of Rural Area}

Rural areas are by implication areas that are not urban. Different countries use different criteria to define their rural areas, including low population figures in the United States, provincial towns outside the cities in New Zealand ${ }^{3}$. In all the definitions, there is the presence of Agriculture and the common factor of limited resources and under-service in public amenities.

In Nigeria, "rural " may be classified into two. There are towns and villages at the fringes of cities which benefit from public utilities in the near-by cities, and there are the typical Nigerian villages which may be recognized by the following characteristics--habitats interspersed with trees in forests, approachable by foot paths, or at the best, untarred or 'were-tarred' roads; inhabitants mostly peasant farmers and low grade artisans and other poor income earners; disease and poor nutrition; lack of useful government attention with regards to public utilities, hospitals, potable water, public electricity supply, and even security of lives and property. 


\section{The Scope of Rural Surgical Practice}

This may be considered under the following headings:

- Geographical scope.

- Scope of performable surgery.

- The surgical practitioner and the scope of his practice.

- New phenomena expanding the scope of Rural Surgery.

- Role of research and innovation.

- The future of Rural surgery

\section{Geographical Scope}

The scope of Rural Surgery is world-wide, wherever people live in small communities away from cities. All such areas are underserved in surgical and other medical needs. Developing countries of Africa and Asia are the worst hit, as the level of poverty in them is high. Rural areas in developed countries, though less well served than their urban counterparts, are much better than the best in the developing world. In both areas however, people often have to travel long distances before accessing surgical help.

\section{Scope of Performable Surgery}

The scope of Rural Surgery encompasses a whole gamut of Surgical Practice. The rural surgeon engages in areas outside the field of traditional General Surgery. Because of his peculiar environment he is obliged to carry out procedures in such fields as Obstetrics and Gynaecology, Urology, Orthopaedics, Ear Nose and throat, Anaesthesia as well as his General Surgery. He deals with all types of emergencies as the man on the spot, without whom prompt help cannot come. The list includes Caesarian Sections, removal of foreign bodies from the ear, nose and throat, initial management of simple fractures, Hip-pinning, appendicectomies, relief of intestinal obstruction, sprapubic cystostomies, catheterization and management of ruptured ectopic tubal pregnancies. In a rural hospital in Northern Nigeria, out of 949 patients operated upon over a nine year period, nearly $50 \%$ were emergency procedures. ${ }^{4}$ On the elective side the list includes prostatectomies, myomectomies, pelvic floor repairs , repair of vesico-vaginal fistulae, bartholin cyst marsupialisation, urethral bouginage, excision of breast lumps, mastectomy, tubal ligation, and thyroidectomies ${ }^{5-8}$. He is truly the surgeon-in-general. He also doubles as a family physician.

Many of these procedures have been learned on the job. The exposure which they provide makes the
Rural Surgeon versatile, and he is the ultimate superspecialist when you consider the extent and spread of his practice, despite any attempt to denigrate him in the present quest for technology and superspecialisation. ${ }^{1}$

\section{The Rural Surgical Practitioner and the Scope of his Practice}

The General Surgeon is the pivot of rural surgical practice. He is ideally suited to occupy this position because of his type of training. But he cannot occupy this position just because he is a general surgeon. He needs to have been well trained well exposed to various fields of surgery, including those outside his field, adaptive and daring. In other words, he needs a wide variety of skills and disciplines ${ }^{5}$ which the present day format of surgical training will not give him. The older surgeons of yester years' training are better suited for this practice as they were trained to be truly General Surgeons in the broad sense of the word. But the present day surgical resident can acquire these skills by taking time off to be exposed to the rural surgery environment as obtains in India. The rural surgeon performs a wider range of procedures than his urban counterpart and his workload is greater. $^{9,10}$

From the foregoing it is inferred that the superspecialist has no place in Rural Surgery as a sole operator, but may come in handy as a visiting consultant. In developed countries of Europe and America, the days of the general practitioner-surgeon are gone. The trained and certified general surgeon has taken his place. But in developing countries this is not the case. General surgeons in Nigeria and elsewhere are reluctant to site their practice or take up appointment in rural areas. Those who do so have often found themselves doing so, often by circumstances, and not by primary choice. Even doctors who were bred in rural areas refuse to return after gaining surgical training ${ }^{11}$. In America there is diminishing interest in General Surgery Residency. All these lead to a dearth of General Surgeons in rural $\operatorname{areas}^{12}$. However, in Nigeria and many other developing countries a large work load of Surgery is performed by general duty doctors who have acquired useful surgical experience in the field. They handle many emergency cases as well as elective cases.

In as much as the scope of Rural Surgery can be very wide, what the individual practitioner can do will depend on, among other things, his level of training, exposure and versatility. If his training has been adequate he can do both minor and major surgical procedures, but if it has been inadequate he may not 
be able to do major surgery. Besides, what he will do will depend on what cases present to him, as certain conditions are more prevalent in certain areas than others. For example, hernias, goiters, urethral strictures, vesico-vaginal fistulae have a predilection for certain districts. Availability of equipment and infrastructure will also determine what cases to do. He may be well trained in cardiac surgery, renal transplantation, or brain surgery, but will not be able to practise them in the non-availability of the tools and environment, such obtains in rural areas.

\section{New Phenomena expanding the Scope of Rural Surgery}

Some State Governments in Nigeria have introduced free medical rotational services to their rural communities, in collaboration with their indigenous doctors resident abroad. This is being done in Imo and Abia States currently.

Surgeons at Ladoke Akintola University Teaching Hospital (LAUTH) have engaged in rotational surgical services in Osun State during which many surgical operations were performed. ${ }^{13}$

In Southern Sudan a team of expatriate consultants established surgical services in remote districts on free treatment basis with equipments, and employed local staff whom they trained..$^{14}$ By these measures, the rural poor have been able to access surgical services at their doorsteps, which would not otherwise have been possible.

These schemes are extensions of the scope of Rural Surgery with emphasis on the use of local staff trained on specific jobs.

The Mobile Theatre Scheme is a relatively new development which takes Surgery closer to the rural people. Full grade surgical theatres are expensive for a single rural hospital to build. One mobile theatre can serve a pool of hospitals. It is fully equipped with all that is needed in an operating theatre. It is in use in New Zealand, India. It is a great stride in expanding the scope of surgical services available in rural areas.

\section{The Role of Innovation, Adaptation and Research in expanding the scope of Rural Surgery}

Inventions, innovations, and research are motivated by need, and in Rural Surgery, there is need, as resources are limited. Many small and solely owned hospitals in Nigeria start in rented buildings which were not built with hospital use in mind. The doctor finds he has to modify the accommodation to suit his needs and may later acquire land to build to his required standard.
In the absence of public water supply, doctors sink bore holes, or construct deep wells fitted with submersible pumps, or even harvest rain water from the roofs of their hospital buildings to underground water tanks. Awojobi O.A. has fabricated many machines for use in his practice ${ }^{6}$. Doctors in India have used water pipes to perform gasless laparoscopy, and perfected the use of potato peels as dressing for burns ${ }^{1}$. They are using mosquito nets in place of the more expensive imported mesh for hernia repair ${ }^{1}$.

Modification of technique includes packing of the prostatic fossa with roller gauze bandage to prevent clot retention after transvesical prostatectomy.

Ajayi O.O. admonishes that appropriate and related research is feasible in rural practice, even if lowtech. $^{5}$

\section{The Challenges of Rural Surgical Practice}

The challenges of rural surgical practice are an invitation to rise up to them and find solutions that will enhance the practice. There ethical and legal issues that must be complied with in order to abide by the rules and regulations of the practice, such as registration of hospital, payment of annual practicing fees, and meeting other government laid down rules. There is also the issue of keeping faith with the patients.

Essential public utilities such as potable water, electricity supply, access roads and even security of life and property may be non-existent.

Trained and quality staff are often difficult to hire and retain. Doctors are reluctant to work in rural areas. The same goes for trained nurses and other ancillary workers who would prefer to search for non-existent jobs in cities. This challenge can be tackled by training local staff on specific assignments, as such trained staff have been found to discharge such functions satisfactorily ${ }^{14,15}$.

Sometimes the surgical practitioner is a loner over a wide area and so has a heavy workload thrust on him. He has limited spare time. This heavy workload is one reason why, in America, there is diminishing interest in General Surgery Residency among doctors.

Tucked away in one remote village, the doctor suffers from a feeling of isolation.He may be unable to make easy contact with colleagues or reach centres for continuing education. Even if he has a computer, internet connectivity may not be available.

Family concerns may be a major issue. A spouse, even though well qualified, may not find suitable employment in the rural area. This is the so-called 
"trailing spouse syndrome". Suitable schools for the children may not exist. There is lack of adequate social life.

Investigation of patients may be incomplete because of lack of facilities. Such investigations will have to out-sourced at inconvenience and increased costs for the patient.

None of the recent medical advances may be available, and the operating theatre may have just the minimum facilities.

Anaesthesia is a major handicap, especially when general anaesthesia is required. Most commonly there is no anaesthesiologist available, doctor or nurse, and the surgeon doctor will direct an assistant to administer some form of anaesthesia. Ketamine, in combination with diazepam, is increasingly being used for general anaesthesia in such a situation.

In some areas, because of poor accessibility, a doctor may not make enough money to keep up the practice. High overhead costs in transportation, maintenance of infrastructure and utilities and staff salaries may make him close down.

There is also the question of competition from nonsurgeons and even non-doctors who will use blackmail as a tool.

Finding replacement for the aging generation of rural surgeons as a way of guaranteeing the future of Rural Surgery is a major challenge ${ }^{16}$.

\section{Conclusion}

Ideally, the scope of Rural Surgery is the scope of Surgery in general. Its need is appreciated all over the world. Its ability to bring services to the door steps of the rural, often poor people, at affordable prices, makes it an important arm of healthcare delivery In Nigeria, most practitioners are non-specialists, who to the best of their ability, are providing life-saving services, especially in emergencies. There is need for trained surgeons to function in rural areas in Nigeria, either full time or part time, to reduce the time lost in referring patients to far away tertiary hospitals and to improve quality of service.

The challenges to rural practice are discouraging, but they can be, and have been successfully managed. It is necessary for the Government to put on ground those essentials which can make the practice continue to be available. It is recommended that grading, or even tarring, of rural roads be pursued visibly, that potable water and pubic electricity supply be extended to more rural areas. Doctors in government service, including specialists, should be made to work in a rural hospital setup, governmentowned or not, for at least one year as a way of ensuring continuity as the older generation retires. The conditions of such service should be especially enticing.

\section{References}

1. Udwadia TE. Surgical care for the poor: A personal perspective Indian Journal of Surgery 2003;65(6):504-509.

2. Malpane A. Rural Surgery in India: Battling against odds the Patients' Doctor, December 4 2006.

3. Yule A. Rural Surgery: New Zealand Family Practice 2002;(2):91-93.

4. Ameh EA. Surgery in a Rural Hospital: Experience from Northern Nigeria East African Medical Journal 1998;75(3):180-183.

5. Ajayi OO, Adebamowo CA. Surgery In Nigeria Arch Surg 1999;134:206-211.

6. Awojobi OA. Rural Surgery in Nigeria-Indian Journal of surgery 2003;65(1)44-46.

7 Umunna JI.Thyroidectomy in a Rural Private Practice Nig Med Pract 1988;16:121-124.

8. Umunna JI. Prostatic Fossa Gauze-packing in the Prevention of Blood Clot Obstruction of the Bladder after Transvesical Prostatectomy WAJM 2010;29(3)184-186.

9. Brughan TA. SAGES 2007 Rural Surgery Panel, Surg.Endosc2008;22:1579-1581.

10. Galanduk S, Mahids et al. Differences and similarities between Rural and Urban Operators, Surgery 2006;140(4):589-696.

11. Mehendale V. Rural Surgery in India, World J Surg 2007;31:1898-1899.

12. Zukerman R, Doly B, Gold M, Borderly I, Dietz P, Jenkins P, Heneghan S. General Surgery Programmes in Small Rurl Newyork Hospitals : A Pilot Survey of Hospital Administrators.The Journal of Rural Health 2006;22(4):339342 .

13. Aderounmu AO, Afolayan SA, Nasiru T, Adeoti, MI, Olaore A, Adelasoye M. Rotational Rural Surgery for the poor in developing countries Tropical Doctor 2008;38:141-144.

14. Meo G, Andreine D, De Bonis U, Cornetto G, Enrico S, Guistetto G, Kiss A, Landra M, et al. A Rural Surgery in Southern Sudan World J Surg 2006;30:496-504.

15. Prabhu RD. A Dilemma of Rural Surgery Indian Journal of Surgery 2003;65(1):102-103.

16. Thompson $\mathrm{M}$ J, Characterising the General Surgery Workforce in Rural America Arch Surg 2005;140:74-79. 